\title{
2 Beyond the technical: The role of emotion regulation in lacrosse officiating
}

3 Andrew P. Friesen ${ }^{1 *}$, Tracey J. Devonport ${ }^{2}$, \& Andrew M. Lane ${ }^{1}$

4 For submission to:

5 Journal of Sports Sciences

6 Submission Date:

$7 \quad$ May 3, 2015

8 Resubmission Date:

9 December 17, 2015

12 Author affiliations:

$13{ }^{1}$ University of Wolverhampton, Faculty of Education, Health \& Wellbeing, Walsall, United

14 Kingdom, apfriesen@gmail.com *Corresponding author

$15{ }^{2}$ University of Wolverhampton, Institute of Sport, Walsall, United Kingdom

$16 *$ Corresponding author

18 Acknowledgements:

19 The authors would like to gratefully acknowledge the support of the Economic and Social

20 Research Council (ESRC; RES-060-25-0044: “Emotion regulation of others and self [EROS])”. 


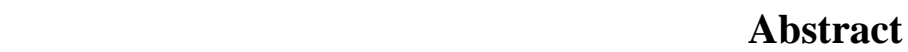

22 Emotions can influence the performance of referees leading to a need to examine emotions

23 experienced, and regulation strategies used by referees. The present study assessed emotions and

24 emotion regulation strategies of 19 referees officiating at an Under-19 Lacrosse World

25 Championship. Using survey methods and focus group interviews, officials responded to five

26 questions: (a) what emotions were experienced? (b) What events elicited emotions? (c) How did

27 lacrosse officials manage their own emotional states prior to, throughout, and following a

28 competitive game? (d) How did officials manage others' emotional states? (e) What were the

29 perceived consequences of these strategies? Results indicate that emotions fluctuated throughout

30 the tournament as referees encountered intrapersonal and interpersonal emotion-eliciting events.

31 These fluctuations are suggested to come from a progressively diminished capacity for emotion

32 regulation. Participants used emotion regulation strategies that could be classified into Gross’

33 (1999) families of emotion regulation strategies, often relying on suppression, emotion

34 contagion, and preventative refereeing. Collectively, the results offer new insights into referee

35 emotion regulation at international events.

36 Keywords: emotion contagion, preventative refereeing, umpires, psychological skills, 37 decision making 


\section{Introduction}

39 Referees represent an important (though sometimes underappreciated) group of sport participants

40 with goals and roles unique from coaches and athletes. Given that referee performance is

41 partially judged by their management of competitive games and athletes, it is unsurprising that

42 referees experience stress during competition (Balmer, et al., 2007; Philippe, Vallerand,

43 Andrianarisoa, \& Brunel, 2009; Lane, Nevill, Ahmad, \& Balmer, 2006; Mahoney, Devonport, \&

44 Lane, 2008). Officials are expected to make accurate decisions, and often whilst under immense

45 pressure similar to competitive athletes (Anshel \& Weinberg, 1999). In an experimental study,

46 Balmer et al. (2007) found that emotional states and mental effort influenced the consistent

47 accuracy of referee decision-making. Therefore researching factors that influence emotional

48 states and mental effort represents a worthwhile line of enquiry.

The influence of emotions on behaviour in sport has been well established (Jokela \&

50 Hanin, 1999; Lane, Beedie, Jones, Uphill, \& Devonport, 2012). While there might be common

51 trends in emotion regulation throughout performance domains, emotion theory has suggested that

52 formal and informal roles within the sport context might have an influence on the emotion

53 regulation of self and others (Friesen, Devonport, Sellars, \& Lane, 2013; Van Kleef, 2009).

54 Conceivably, for example, the authority over gameplay bestowed to referees might manifest in

55 different strategies to manage players and coaches' emotions. Similarly, the referee’s goal is to

56 maintain fair and safe gameplay while the goal of coaches and players is to win the match. Given

57 the relationship between goals and emotions (Tamir, 2015), we suggest that the difference in

58 goals between referees and coaches and athletes might lead to different emotion eliciting events

59 and regulation strategies. Given calls to view referees as performers, and for a greater volume of

60 research to be focused on them (Philippe et al., 2009), examining the influence of emotion 
61 regulation on performance among referees offers great potential in informing applied work with

62 sports officials. It is commonly agreed that interventions should be founded on theory and

63 research (Michie, Rothman, \& Sheeran, 2007), and to date, there is little research examining how

64 referees regulate their own and players emotions experienced in competition.

Emotion regulation is proposed to be a controlled process that involves the initiation,

66 maintenance and modification of the occurrence, intensity, and duration of feeling states

67 (Eisenberg, Fabes, Guthrie, \& Reiser, 2000; Gross \& Thompson, 2007). This can include the

68 regulation of one's own feelings and the regulation of other people's feelings that are monitored in

69 comparison to a desired standard (Niven, Totterdell, \& Holman, 2009). When an individual

70 identifies discrepancies between current emotion states and those preferred or deemed, optimal or

71 required, then regulation is required (Webb, Gallo, Miles, Gollwitzer, \& Sheeran, 2012). In

72 refereeing, calmness is proposed to be an emotion state linked to optimal performance (Anshel \&

73 Weinberg, 1995). Attaining this state may require the attenuation of intense emotions such as

74 anxiety and anger frequently experienced whilst officiating (Anshel \& Weinberg, 1995, Balmer et

75 al., 2007).

76 Strategies used to regulate emotions have been organised according to numerous

77 classification schemes (e.g., Parkinson \& Totterdell, 1999; Koole, 2009). Gross and Thompson’s

78 (2007) process model of emotion regulation highlights five families of emotion regulation

79 strategies along a temporal continuum of when the strategies are employed during emotion

80 generation. The first four emotion regulation families (i.e., situation selection, situation

81 modification, attentional deployment and cognitive change) are described by Gross (1999) as

82 antecedent-focused strategies because these strategies occur before appraisals give rise to full-

83 blown emotional responses. These strategies may be contrasted with the fifth emotion regulation 
84 family, response modulation which occurs late in the emotion-generative process, after the

85 emotional responses are generated (Gross \& Munoz, 1995; Gross \& Thompson, 2007). trigger emotions we would like to experience. Situation modification involves modifying the situation directly so as to alter its emotional impact. Attentional deployment involves redirecting

89 attention within a given situation in order to influence emotional responses. Regulatory

90 behaviors focussed on cognitive change seek to change one or more emotion-antecedent

91 appraisals in a way that alters the situation's emotional significance. This is achieved by

92 changing how we think either about the situation itself or about our capacity to manage the

93 situational demands. Finally, response modulation strategies influence physiological,

94 experiential, or behavioural responses relatively directly after the emotion has occurred (Gross \& 95 Thompson, 2007).

96 Emotion regulation can further be distinguished according to whether strategies are

97 targeted toward the person's own feeling states (i.e., intrapersonal emotion regulation) or targeted

98 toward another person's feeling states (i.e., interpersonal emotion regulation). There has been

99 sustained research interest in emotion regulation (see Koole, 2009; Lane et al., 2012; Webb, Miles,

100 \& Sheeran, 2012) although this has tended to focus on regulating one’s own emotions. Recent

101 research has seen an increase in research examining interpersonal emotion regulation (Friesen, et

102 al., 2013; Niven et al., 2009). Given the interplay between intra and interpersonal emotion

103 regulation, there is a growing trend to simultaneously examine both types together (e.g., Stanley,

104 Lane, Beedie, Friesen, \& Devonport, 2012; Tamminen \& Crocker, 2013).

105 An example is provided by Tamminen and Crocker (2013) who examined intra and

106 interpersonal emotion regulation within a high performance female curling team. Their analysis 
107 revealed that teammates tried to regulate their own emotions through strategies such as body

108 language and self-censorship. Teammates attempted to regulate each others' emotions by

109 providing positive or technical feedback, humour, cueing teammates about their emotions, pro-

110 social actions and indirect actions. They further identified numerous factors believed to influence

111 emotion regulation (e.g., length of time together, team dynamics or cohesion, context, social

112 norms and team roles, and seeking support outside the team).

113 Given the applied value of investigating emotion regulation among sports officials at

114 world championship competition, the aim of the research is to investigate the following five

115 questions: (a) What emotions are experienced by officials at a major world tournament? (b) What

116 factors or circumstances elicit emotions during officiating? (c) How do lacrosse officials manage

117 their own emotional states prior to, throughout, and following a competitive game? (d) How do

118 lacrosse officials perceive and manage the emotional states of their fellow officiating crew? (e)

119 What are the perceived consequences to these emotion regulation attempts?

\section{Method}

122 Participants were 19 lacrosse officials (18 men, 1 woman, $M_{\text {age }}=36.5$, age range: $27-56$ years)

123 who officiated at a U19 World Lacrosse Championship tournament. The nationality of these

124 referees included American, Australian, British, Canadian, German, Iroquois, Japanese, and

125 Slovakian. All participants could communicate in English. These participants had an average of

12611.5 years of officiating experiencing with an average of 4.5 years of experience officiating at an

127 international level of competition. These participants had officiated an average of 3 international 128 tournaments (ranging from 1 to 8 ). 
130 The authors obtained ethics approval for the study through the author's university ethics board.

131 The first author was sent to the tournament to collect data and spent the entirety of the

132 tournament with the participants and was able to build rapport during meal and leisure time away

133 from the competition. Mixed methods data collection consisted of emotion diaries that were

134 completed before each game, and focus group interviews that occurred following games. It is

135 worth noting that during tournament play, referees' judgements and actions were assessed by an

136 adjudication committee who would determine referee opportunities and groupings for playoffs

137 and championships matches.

\section{Emotion Diaries}

139 Participants were asked to record their emotions before each game throughout the course of the 140 tournament. Emotions were recorded on a 5-point rating scale ranging from 1 (not at all) to 5

141 (extremely) to report the extent to which 11 distinct emotions representing all areas of Russell's

142 (1980) circumplex model of emotion were experienced (i.e., happy, angry, calm, downhearted,

143 energetic, still, sluggish, enthusiastic, anxious, guilty and proud). Emotions were rated in terms

144 of "how participants were feeling right now" (Lane \& Terry, 2000) These emotion diaries also

145 asked participants to measure the extent to which they had difficulty regulating their own and

146 others' emotional states and their confidence to regulate these emotions in the last 24 hours.

147 Lastly, participants were asked to rate the perceived extent their emotions helped their

148 performance and the extent to which they were satisfied with their performance. These

149 perceptions were recorded on a 5-point rating scale ranging from 1 (not at all) to 5 (extremely).

Focus Group Interviews

151 Each participant took part in at least one semi-structured focus-group interview (some

152 participants participated in multiple interviews). These interviews were conducted onsite at the 
153 tournament shortly following completed games and averaged 19 minutes in length. These

154 interviews focused on discussing emotion-eliciting events, attempts to manage own and others'

155 emotions, and consequences of regulatory efforts. The preceding game acted as a prompt for the

156 focus interviews. Specific questions included: "Please share some of the things that caused

157 intense emotions during the game;" "How did you attempt to manage your emotions during and

158 before the game;" "How did you manage the emotions of your fellow referees, athletes, and

159 coaches?” Responses from emotion diaries were also used as prompts for the interviews. The

160 interviewer tried to encourage verbal responses from each participant to ensure each participant

161 contributed to the discussion.

163 In order to analyse the data in a concise manner, quantitative data detailing emotions experienced 164 and subsequent consequences were grouped together according to when they coincided with 165 changes in the tournament format: Round-robin (Day 1 to Day 4), Playoffs (Day 5 to Day 7), and

166 Finals (Day 8 to Day 9). The rationale for this grouping was based on the assumption that

167 because the meaningfulness of the games was changing because of when they occurred, so too

168 might the emotions experienced. As the aim was to investigate how emotions changed in 169 combination, multivariate analysis of variance (MANOVA) was used. This option is preferred to 170 running multiple univariate tests (Tabachnick \& Fidell, 2013). Qualitative data analysis was

171 assisted using NVivo 9 software. Emotion-eliciting events were classified into intra- and

172 interpersonal sources of emotions. A deductive analysis following Gross' (1998) process model

173 of emotion regulation was used to contextualise intra- and interpersonal emotion regulation

174 strategies. There were no reported strategies that could not be categorised into any of Gross' five 175 families. 


\section{Results}

178 Self-reports of collective experienced emotions indicate that referees' emotions varied through

179 the Round-robin, Playoffs, and Finals. As detailed in Figure 1, the following emotions

180 collectively peaked at during Round-robin: Anxiety, downheartedness and guilt. The following

181 emotions peaked during Playoffs: Happiness, pride, enthusiasm, and calmness. The following

182 emotions peaked at the Finals: Energetic, stillness, sluggishness, and anger. It is worth noting

183 that happiness, pride, enthusiasm, energetic, and calmness as show in Figure 1 remained the

184 emotions perceived as most intensely felt throughout the duration of the tournament.

187 Results from a MANOVA revealed the consequences of emotion regulation as they unfolded

188 throughout the course of the tournament and indicated an overall significant effect (Wilks’ $\lambda_{2.886}$

$189=.521, P=.002$, partial $\left.\eta^{2}=.278\right)$. Results revealed significant differences in the perceived

190 difficulty and confidence in being able to regulate one's own emotions throughout the

191 tournament. Specifically, the perceived difficulty to regulate own emotions reduced (lowest

192 during Playoffs) and perceived confidence to regulate own emotions increased (highest during

193 Playoffs). Furthermore, perceptions of emotions helping performance and satisfaction with

194 performance increased as the tournament progressed. See Table I.

[Please insert Table I here]

197 Events and circumstances that triggered emotions in our referee sample are presented in Table II.

198 Emotion-eliciting events and circumstances were categorised into two higher-order themes 
199

200

201

202

203

204

205

206

207

208

209

210

211

212

213 Emotion regulation experiences and data were reported from lacrosse referees whilst they

214 officiated at an Under 19 World Championship tournament. The participants indicated that their

215 emotional states fluctuated throughout the tournament, as did their perceived difficulty and

216 confidence in managing their own and others’ emotions. Additionally, participants reported

217 intra- and interpersonal events that elicited emotions and numerous strategies to help manage

218 these emotions that were grouped according to Gross' (1998) process model of emotion

219 regulation strategies.

220

221

representing a dichotomy in the sources of the events: intrapersonal (emanating from situations internal to the referee) and interpersonal (emanating from sources external to the referee).

Emotion-eliciting events were further classified into 11 second-order themes.

[Please insert Table II here]

\section{Emotion Regulation Strategies}

Intra- and interpersonal emotion regulation strategies were classified in accordance with Gross’ five families of emotion regulation strategies. Interpersonal emotion regulation strategies were further distinguished between those targeted at coaches and athletes, and those targeted at fellow officials. This was deemed appropriate as interpersonal emotion regulation theory and research has demonstrated the moderating effect of social-contextual factors (in this case, relationship power differential) in regulating others’ emotions (Van Kleef, 2009). Table III presents intraand interpersonal emotion regulation strategies.

[Please insert Table III here]

\section{Discussion}


222 leading up to competition (Cerin, Szabo, Hunt, \& Williams, 2000; Hanton, Thomas, \& Maynard,

223 2004). This suggests that during longitudinal events, fluctuations in felt emotions are likely to

224 occur among athletes and officials; and consequently this might change the interpersonal

225 dynamics of emotion eliciting and regulatory processes. Pleasant emotions such as calm, pride,

226 happiness, and enthusiasm peaked during Playoffs thereafter decreasing towards the Finals. This

227 coincided with an increase in unpleasant emotions such as anger, downhearted and sluggishness

228 towards the end of the tournament. Concurrent to these changes in felt emotions were significant

229 changes in perceived emotion regulation abilities. Specifically, confidence in regulating own

230 emotions peaked and perceived difficulty in managing own emotions was at its lowest during

231 Playoffs. From mid to late tournament, perceptions of confidence in managing emotions reduced

232 whilst perceived difficulty in managing emotions increased.

233 It is conceivable that as the tournament progressed, referees might have been

234 experiencing a diminished capacity to regulate emotions, and that consequently emotion

235 regulation required more effort. In order to perform consistently, a referee must display self-

236 control, and according to the Strength Model (Baumeister, Vohs \& Tice, 2007), all forms of self-

237 control; including emotion regulation, are proposed to use a limited resource (Gailliot et al.,

238 2007). Using the metaphor of self-control acting like a muscle, repeated use consumes a limited

239 resource resulting in temporary depletion—akin to a muscle becoming fatigued after exercise.

240 This compromises an individual's capacity to exert self-control in subsequent tasks. Nevertheless

241 much like a muscle, with rest and relaxation, the resource is replenished and the capacity for self-

242 control is restored (Gailliot et al., 2007). Thus, referees regulating emotions and making

243 decisions in stressful environments could be susceptible to performance decrements via resource

244 depletion. An indication of depletion is perhaps evidenced in the present study by an increase in 
245 feelings of sluggishness, downheartedness and anger that were collectively demonstrated by

246 participants between the Playoffs and Finals. It may also be evidenced by an increase in

247 perceived difficulties in regulating own emotions, and decreased confidence to regulate own

248 emotions. Further research could examine these plausible associations under carefully controlled 249 conditions.

250 Referees concurrently reported significant increases in both the instrumental value of

251 their emotions and perceived satisfaction with their performance as the tournament progressed.

252 This seemingly contradictory finding may be partially explained by research exploring meta-

253 emotional beliefs regarding the functional role of emotions (Hanin, 2000; Robazza, Bortoli, \&

254 Hanin, 2006; Robazza, Pellizzari, \& Hanin, 2004). A referee might intentionally elicit an

255 unpleasant emotion state such as anger if they believe that it might assist in the pursuit of desired

256 performance consequences (cf. Robazza et al., 2004). In the context of the present study, in

257 seeking to manage increased intensities of sluggishness that might be anticipated as a tournament

258 progresses, we suggest that referees might have instrumentally elevated feelings of anger (or

259 allowed anger, elicited from an external event, to remain unregulated). Anger is known to be an

260 energising emotion (Hanin, 2000), and as such it might help manage increased feelings of

261 sluggishness. This contention might explain increases in scores for the instrumental value of felt

262 emotions. It might also help explain increased ratings of performance satisfaction across the

263 tournament as referees may take into account the stage of the tournament and anticipated fatigue

264 (physical and mental). Further enquiry to reconcile these seemingly conflicting perspectives is

265 warranted.

266 The emotion-eliciting events derived from focus interviews were broadly themed as

267 intrapersonal and interpersonal emotion-eliciting events. Findings of the present study offer 
268 support for previous research that has identified the following emotion-eliciting events among

269 sports officials: interpersonal (i.e., peers, coaches, athletes) interactions or conflicts; conflict

270 between officiating and work or family demands; fear of failure; making errors; making

271 controversial calls; verbal abuse; internal physiology; evaluation by a supervisor or assessor; and

272 meaningful (e.g., playoff) games (Anshel \& Weinberg, 1995, 1999; Balmer et al., 2007;

273 Goldsmith \& Williams, 1992; Mason \& Lovell, 2000; Rainey, 1995; Stewart \& Ellery, 1998;

274 Voight, 2009). The two most reported emotion-eliciting events were interpersonal interactions

275 and game meaning. Interpersonal interactions represent a noteworthy finding as it suggests that

276 referees might be susceptible to interpersonal emotion regulation strategies implemented from

277 coaches and athletes. If the purpose of interpersonal emotion regulation in sport is to bring about

278 behavioural (i.e., performance) changes (see Friesen, Lane, et al., 2013), then the findings

279 suggest that coaches and athletes might be able to influence the performance, decision-making,

280 and subsequent calls of referees and officials. An applied implication of this study then is that it

281 might be beneficial to educate referees about possible strategies coaches and athletes might use

282 to bias referees’ calls.

283 The meaningfulness of the game was also frequently reported as an emotion-eliciting

284 event. This is unsurprising as the context for this study was of World Championship calibre.

285 Complementing the athletes' perceived meaningfulness of the tournament, one of the referees

286 also reported, "this is a World Championship for us too." As such, the tournament represented a

287 significant amount of prestige and source of pride for the referee participants. This was

288 supported in the results as pride was the highest reported emotion throughout the tournament.

289 Although sport psychology researchers have studied instrumental performance effects in sport

290 (e.g., Lane, Beedie, Devonport, \& Stanley, 2011), studies have largely ignored the potential 
291 performance effects of pride. Given that broader psychology has begun to research the 292 behavioural effects of pride (e.g., Carver, Sinclair, \& Johnson, 2010; Tracy, Shariff, \& Cheng, 293 2010; Williams \& DeSteno, 2009), the results of this study suggest the performance effects of 294 pride would be a worthwhile line of enquiry for sports psychology researchers. Referees utilised strategies from Gross’ (1999) five emotion regulation families to 296 regulate their own emotions as well as the emotions of others. Some of these strategies are 297 common to the sports psychology vernacular, for example attentional control (e.g., Wulf, 2013) 298 and self-talk (e.g., Hardy, 2006). Participants also reported a number of strategies that represent 299 new avenues for study in sport. For example, many of the referees reported instances of 300 controlling their emotional expressions to hide their experienced feelings. For example, the 301 referees reported that a common emotion-inducing event was making judgemental rulings (i.e., 302 the "50/50 call"). Despite the brief anxiety that these calls stimulated, referees reported the 303 benefit of maintaining a composed, confident and even aggressive demeanour. Referees believed 304 that this type of emotional labour or surface acting (e.g., Totterdell \& Holman, 2003) precluded 305 athletes and coaches to second-guess their judgements and deterred heightened unpleasant 306 emotions. Typically in work psychology, emotional labour has been associated with unpleasant 307 feelings and intrapersonal consequences such as exhaustion and burnout (e.g., Kenworthy, Fay, 308 Frame, \& Petree, 2014). In our study, however, referees reported intense pleasant emotions 309 throughout the duration of the tournament (i.e., pride, happy, enthusiastic, energetic). Our 310 finding that referees could consistently employ surface acting strategies yet maintain heightened 311 pleasant emotions represents an opportunity for future research. Pertaining to the regulation of others' emotions, referees in this study exhibited instances

313 of emotion contagion whereby they would try to regulate their own emotions in an attempt to 
314 facilitate a "contagious" effect whereby their crewmembers could also experience the desired

315 emotion. Zaki and Williams (2013) referred to this process as intrinsic interpersonal emotion

316 regulation, and this has already been identified in sports team research (e.g., Tamminen \&

317 Crocker, 2013). Given that teammates (i.e., both athletes and officials) have shared goals in

318 competition, it is likely that an individual desiring to bring about perceived performance effects

319 by regulating their emotions might desire to have their teammates experience the same emotions,

320 intrinsic interpersonal emotion regulation represents a valuable avenue for new research in sport.

321 Additionally, referees in this study talked at length about a strategy used to regulate

322 athletes' emotions called "preventative refereeing." This strategy, classified within the situation

323 selection family, was focussed on refereeing in accordance with the game score in lopsided

324 games where the end result is already anticipated (e.g., a score of 10 to 1 with mere minutes left

325 to play). This was a preventive strategy mainly intended to control and prevent aggression from

326 the losing team. Here referees would look to ensure that the trailing team was given enhanced

327 opportunity to maintain ball possession or tactical advantage. By doing so, the referees hoped to

328 avoid situations where the losing team would act inappropriately on their feelings of anger or

329 desperation and commit a violation that resulted in an injury on a player from the winning team.

330 Naturally, the winning team often objected to this perceived favouritism and the referees

331 responded with additional interpersonal emotion regulation strategies to calm down athletes and

332 coaches on the winning team. Usually, this was in the form of changing cognitive appraisals of

333 the situation by reminding the winning team that the desired effect of the referee's actions was to

334 ensure the losing team would not injure any of their players. This approach was reported to help

335 reduce tensions in the winning team. This is not a new revelation as a study examining refereeing

336 in handball found that referees and officials sometimes adapt the rules of the game to suit the 
337 conditions and skills of the players (Souchon, Cabagno, Traclet, \& Rascle, 2004). Nevertheless,

338 this type of judgemental refereeing, embedded in the art of officiating, has not received much

339 scientific scrutiny and represents an intriguing avenue for future research on referees, umpires,

340 and officials.

341 A number of limitations from the current study need to be underscored. Firstly, there is a

342 possibility that emotion diary data might have been influenced by the focus group interviews.

343 For example, if one referee learned about a new strategy for regulating emotions early in the

344 tournament from an interview and subsequently applied this strategy for the remainder, this

345 might have influenced their ratings to such emotion diary responses as confidence to regulate

346 emotions because they had been provided with a new resourceful strategy. Additionally, the

347 study relied on self-report data. This might be problematic as it relies on the participants'

348 awareness to answer questions as to what might have triggered their emotions and the extent to

349 which they were successful in regulating others' emotions. The use of self-report data also

350 precludes us from determining whether there were any measurable effects of regulation. While

351 acknowledging the small sample size, the current study has provided some valuable insights into

352 the refereeing experience at a World Championship tournament. The intra- and interpersonal

353 emotion regulation strategies reported in this study represents a valuable resource for future

354 intervention-based empirical work that might attempt to test the efficacy or moderating factors of

355 these strategies. Admittedly, this study utilised a predominately male sample as was only

356 permitted by the tournament circumstances. Given the gender differences in emotion regulation

357 as reported by the literature (e.g., Gross \& John, 2003) future research should seek to have equal

358 representation between the sexes. 
359

360

361

362

363

364

365

366

367

368

369

370

371

372

373

374

375

376

377

378

379

380

381

\section{References}

Anshel, M. H., \& Weinberg, R. S. (1995). Coping with acute stress among American and Australian basketball referees. Journal of Sport Behavior, 19, 180-203.

Anshel, M. H., \& Weinberg, R. S. (1999). Re-examining coping among basketball referees following stressful events: implications for coping interventions. Journal of Sport Behavior, 22, 141-161.

Balmer, N. J., Nevill, A. M., Lane, A. M., Ward, P., Williams, M. A., \& Fairclough, S. A. (2007). Influence of crowd noise on soccer refereeing consistency. Journal of Sport Behavior, 30, 130-145.

Baumeister, R. F., Vohs, K. D., \& Tice, D. M. (2007). The strength model of self-control. Current Directions in Psychological Science, 16, 351-355. doi: 10.1111/j.14678721.2007.00534.x

Carver, C. S., Sinclair, S., \& Johnson, S. L. (2010). Authentic and hubristic pride: Differential relations to aspects of goal regulation, affect, and self-control. Journal of Research in Personality, 44(6), 698-703. doi:10.1016/j.jrp.2010.09.004

Cerin, E., Szabo, A., Hunt, N., \& Williams, C. (2000). Temporal patterning of competitive emotions: A critical review. Journal of Sports Sciences, 18, 605-626. doi:10.1080/02640410050082314

Eisenberg, N., Fabes, R. A., Guthrie, I. K., \& Reiser, M. (2000). Dispositional emotionality and regulation: Their role in predicting quality of social functioning. Journal of Personality and Social Psychology, 78, 136-157. doi:10.1037//0022-3514.78.1.136

Friesen, A., Devonport, T. J., Sellars, C. N., \& Lane, A. M. (2013). A narrative account of decision-making and interpersonal emotion regulation using a social-functional approach 
Running title: EMOTION REGULATION IN LACROSSE OFFICIATING

382

383

384

385

386

387

388

389

390

391

392

393

394

395

396

397

398

399

400

401

402

403

404

405

to emotions. International Journal of Sport \& Exercise Psychology

doi:10.1080/1612197X.2013.773664

Friesen, A. P., Lane, A. M., Devonport, T. J., Sellars, C. N., Stanley, D. N., \& Beedie, C. J. (2013). Emotions in sport: Considering Interpersonal regulation strategies. International Review of Sport and Exercise Psychology, 6, 139-154.

doi:10.1080/1750984X.2012.742921

Gailliot, M. T., Baumeister, R. F., DeWall, C. N., Maner, J. K., Plant, E. A., Tice, D. M., et al. (2007). Self-control relies on glucose as a limited energy source: Willpower is more than a metaphor. Journal of Personality and Social Psychology, 92, 325-336. doi: 10.1037/0022-3514.92.2.325

Goldsmith, P. A., \& Williams, J. M. (1992). Perceived stressor for football and volleyball officials from three rating levels. Journal of Sport Behavior, 15, 106-118.

Gross, J. J. (1998). Antecedent and response focused emotion regulation: Divergent consequences for experience, expression and physiology. Journal of Personality and Social Psychology, 74, 224-237.

Gross, J. J. (1999). Emotion Regulation: Past, present, future. Cognition and Emotion, 13, 551573. doi:10.1080/026999399379186

Gross, J. J., \& John, O. P. (2003). Individual differences in two emotion regulation processes: implications for affect, relationships, and well-being. Journal of Personality and Social Psychology, 85, 348-362. doi:10.1037/0022-3514.85.2.348

Gross, J. J., \& Muñoz, R. F. (1995). Emotion regulation and mental health. Clinical psychology: Science and practice, 2, 151-164.

Gross, J. J., \& Thompson, R.A. (2007). Conceptual foundations. In J.J. Gross (Ed.), Handbook of emotion regulation (pp. 3-26). New York, NY: The Guilford Press. 
406

407

408

409

410

Hanin, Y. L. (2000). Emotions in sport. Human Kinetics.

Hanton, S., Thomas, O., \& Maynard, I. (2004). Competitive anxiety responses in the week leading up to competition: The role of intensity, direction and frequency dimensions. Psychology of Sport and Exercise, 5, 169-181. doi:10.1016/S1469-0292(02)00042-0

Hardy, J. (2006). Speaking clearly: A critical review of the self-talk literature. Psychology of Sport and Exercise, 7(1), 81-97. doi:10.1016/j.psychsport.2005.04.002

Jokela, M., \& Hanin, Y. L. (1999). Does the individual zones of optimal functioning model discriminate between successful and less successful athletes: A meta-analysis. Journal of Sports Sciences, 17, 873-887. doi:10.1080/026404199365434

Kenworthy, J., Fay, C., Frame, M., \& Petree, R. (2014). A meta-analytic review of the relationship between emotional dissonance and emotional exhaustion. Journal of Applied Social Psychology, 44, 94-105. doi:10.1111/jasp.12211

Koole, S. L. (2009). The psychology of emotion regulation: An integrative review. Cognition \& Emotion, 23, 4-41. doi:10.1080/02699930802619031

Lane, A. M., Beedie, C. J., Devonport, T. J., \& Stanley, D. M. (2011). Instrumental emotion regulation in sport: relationships between beliefs about emotion and emotion regulation strategies used by athletes. Scandinavian journal of medicine \& science in sports, 21, e445-e451. doi:10.1111/j.1600-0838.2011.01364.x

Lane, A. M., Beedie, C. J., Jones, M. V., Uphill, M., \& Devonport, T. J. (2012). The BASES expert statement on emotion regulation in sport. Journal of Sports Sciences, 30(11), 1189-1195. doi:10.1080/02640414.2012.693621 
Running title: EMOTION REGULATION IN LACROSSE OFFICIATING

427 Lane, A. M., Nevill, A. M., Ahmad, N. S., \& Balmer, N. (2006). Soccer Referee Decision-

428 Making: ‘Shall I Blow The Whistle?’ Journal of Sports Science and Medicine, 5, 243-

429253.

430 Lane, A. M., \& Terry, P. C. (2000). The nature of mood: Development of a conceptual model $431 \quad$ with a focus on depression. Journal of Applied Sport Psychology, 12(1), 16-33.

432 Mahoney, A., Devonport, T., \& Lane, A. M. (2008). Interval feedback and self-efficacy of 433 netball umpires. Journal of Sports Sciences and Medicine, 7, 39-46

434 Mason, C., \& Lovell, G. (2000). Attitudes, expectations and demands of English Premier League 435 football association referees. Football Studies, 3, 88-102.

Michie, S., Rothman, A. J., \& Sheeran, P. (2007). Current issues and new direction in Psychology and Health: Advancing the science of behavior change. Psychology \& Health, 22, 3, 249-253. doi:10.1080/14768320701233582

Parkinson, B., \& Totterdell, P. (1999). Classifying affect-regulation strategies. Cognition and

Niven, K., Totterdell, P., \& Holman, D. (2009). A classification of controlled interpersonal affect regulation strategies. Emotion, 9, 498-509. doi:10.1037/a0015962

443 Philippe, F. L., Vallerand, R. J., Andrianarisoa, J., \& Brunel, P. (2009). Passion in referees: \& Exercise Psychology, 31, 77-96.

Rainey, D. W. (1995). Stress, burnout, and intention to terminate among umpires. Journal of Sport Behavior, 18, 312-324. 
448

449

450

451

452

453

454

455

456

457

458

459

460

461

462

463

464

465

466

467

468

469

470

Robazza, C., Bortoli, L., \& Hanin, Y. (2006). Perceived effects of emotion intensity on athletic performance: a contingency-based individualized approach. Research Quarterly for Exercise and Sport, 77, 372-385. doi: 10.1080/02701367.2006.10599371

Robazza, C., Pellizzari, M., \& Hanin, Y. (2004). Emotion self-regulation and athletic performance: An application of the IZOF model. Psychology of Sport and Exercise, 5, 379-404. doi:10.1016/S1469-0292(03)00034-7

Russell, J. A. (1980). A circumplex model of affect. Journal of Personality and Social Psychology, 39, 1161-1178. doi:10.1037/h0077714

Souschon, N., Cabagno, G., Traclet, A., \& Rascle, O. (2004). Referees’ Decision Making in Handball and Transgressive Behaviours: Influence of Stereotypes about Gender of Players? Sex Roles, 51, 445-453. doi:10.1023/B:SERS.0000049233.28353.f0

Stanley, D. M., Lane, A. M., Beedie, C. J., Friesen, A. P., \& Devonport, T. J. (2012). Emotion regulation strategies used in the hour before running. International Journal of Sport and Exercise Psychology, 10(3), 159-171. doi:10.1080/1612197X.2012.671910

Stewart, M. J., \& Ellery, P. J. (1998). Sources and magnitude of perceived psychological stress in high school volleyball officials. Perceptual and Motor Skills, 87, 1275-1282. doi:10.2466/pms.1998.87.3f.1275

Tabachnick, B. G., and Fidell, L. S. (2013). Using multivariate statistics, 6th ed. Boston: Pearson.

Tamir, M. (2015). Why do people regulate their emotions? A taxonomy of motives in emotion regulation. Personality and Social Psychology Review, doi:10.1177/1088868315586325.

Tamminen, K. A., \& Crocker, P. R. (2013). “I control my own emotions for the sake of the team”: Emotional self-regulation and interpersonal emotion regulation among female 
471

472

473

474

475

476

477

478

479

480

481

482

483

484

485

486

487

488

489

high-performance curlers. Psychology of Sport and Exercise, 14(5), 737-747. doi:10.1016/j.psychsport.2013.05.002

Totterdell, P., \& Holman, D. (2003). Emotion regulation in customer service roles: Testing a model of emotional labor. Journal of occupational health psychology, 8, 55-73. doi:10.1037/1076-8998.8.1.55

Tracy, J. L., Shariff, A. F., \& Cheng, J. T. (2010). A naturalist's view of pride. Emotion Review, 2, 163-177. doi: 10.1177/1754073909354627

Van Kleef, G. A. (2009). How emotions regulate social life. Current Directions in Psychological Science, 18, 184-188. doi:10.1111/j.1467-8721.2009.01633.x

Voight, M. (2009). Sources of stress and coping strategies of US soccer officials. Stress and Health, 25, 91-101. doi:10.1002/smi.1231

Webb, T. L., Gallo, I. S., Miles, E., Gollwitzer, P. M., \& Sheeran, P. (2012): Effective regulation of affect: An action control perspective on emotion regulation, European Review of Social Psychology, 23, 143-186. doi:10.1080/10463283.2012.718134

Webb, T. L., Miles, E., \& Sheeran, P. (2012). Dealing with feeling: A meta-analysis of the effectiveness of strategies derived from the process model of emotion regulation. Psychological Bulletin, 138, 775-808. doi:10.1037/a0027600

Williams, L. A., \& DeSteno, D. (2009). Pride Adaptive Social Emotion or Seventh Sin?. Psychological Science, 20, 284-288. doi: 10.1111/j.1467-9280.2009.02292.x 
490 Wulf, G. (2013). Attentional focus and motor learning: a review of 15 years. International 491 Review of Sport and Exercise Psychology, 6, 77-104.

492 doi:10.1080/1750984X.2012.723728

493 Zaki, J., \& Williams, W. C. (2013). Interpersonal emotion regulation. Emotion, 13, 803-810.

494 doi:10.1037/a0033839 